\title{
PECULIARITIES OF DESTRUCTION MECHANISM OF POLYMERIC INTUMESCENT FIRE PROTECTIVE COATINGS
}

\author{
Romualdas MAČIULAITIS ${ }^{1}$, Mindaugas GRIGONIS ${ }^{2}$, Jurgita MALAIŠKIENE ${ }^{3 *}$, \\ Donatas LIPINSKAS ${ }^{2}$ \\ ${ }^{1}$ Faculty of Civil Engineering, Vilnius Gediminas Technical University, Sauletekio al. 11, \\ LT-10223 Vilnius, Lithuania \\ ${ }^{2}$ Fire Research Centre of the Fire and Rescue Department under the Ministry of the Interior of the Republic of \\ Lithuania, Švitrigailos g. 18, LT-03223 Vilnius, Lithuania \\ ${ }^{3}$ Laboratory of Composite Materials, Institute of Building Materials, Faculty of Civil Engineering, \\ Vilnius Gediminas Technical University, Linkmenu g. 28, LT-08217 Vilnius, Lithuania
}

Received 09 October 2017; accepted 16 January 2018

\begin{abstract}
The article describes the destruction mechanism of intumescent fire protective paint coatings at the time of their aging under the impact of simulated climatic factors. Steel plates covered in anti-corrosion varnishes and intumescent fire protective paint coatings of several types and different composition were used in the research, while certain samples were also additionally covered in protective coatings protecting from environmental effects. SEM, DTA and FT-IR researches were conducted on control samples and samples after aging. Aging was performed in 3 ways: according to regimes I and II in the laboratory and having stored them for 12 months under the outdoor conditions under the roof. The aging mechanism of materials was determined to be very similar when using different methods of aging: with increasing number of cycles, the extent of damage to the surfaces and their diversity increase. In all cases, chemical material changes were observed after artificial aging cycles compared to control samples. In aged samples, there were some new connections occurring, while others changed or disappeared judging from the number of waves and intensity of peaks, which shows that certain compounds form, while others change and disintegrate under the influence of environmental heat and mass exchange.
\end{abstract}

Keywords: polymeric intumescent coatings, destruction mechanism, steel, fire resistance.

\section{Introduction}

From the modern perspective, intumescence mechanism of fire protective coatings is determined by the following factors: the binder becomes softer when affected by flames or high temperature and, with the release of gas, the coating intumescences. At the same time, a carbon layer forms due to the hydration of polyhydric compounds with the adherence of acids. The selection of certain compounds and components allows eliminating the leakage of softened layers from the heated surface, while adding respective additives allows structuring the resulting foam and slowing down the burning of the coating (Bodzay et al. 2011).

The impact of intumescent fire protective paint coatings on steel surfaces is examined considering physical and chemical properties of coatings and heat and mass exchange processes. Changes in chemical indicators manifest for chemical effects of inhibitors (vapour phase) and burning (oxidation reaction) under fire conditions (Duquesne et al. 2005). When using ammonium polyphosphates in water-soluble or dilutable binders, there is a need to adjust $\mathrm{pH}$ of film-forming substances protecting them from too fast coagulation and aging. Carboxymethyl cellulose, dextrin, casein or tetramethylenediamine, hexamethyltetramine binders are used for this purpose (Dimanshteyn, Barone 2006; Hairston et al. 2006; Zhou et al. 2008).

Assessing the process of aging of intumescent fire protective coatings is very difficult due to the complexity of the composition of the paint itself and of its structure. Aging is a process when physical properties of a material change under certain natural environmental conditions regardless of the fact that initial operational requirements have been met. The environment may strongly affect not

*Corresponding author. E-mail: jurgita.malaiskiene@vgtu.lt 
only the layer of intumescent fire protective coating, but also the thickness of anti-corrosive soil layer and properties of the additional protective coating layer (EN ISO 12944-2:2000 2000). Talking about steel protection in general, EN ISO 12944-2:2000 (2000) standard provides definitions of several impact environments, assessing them from the perspective of corrosiveness according to respective rates of corrosion of carbon steel. This standard shows the relation between categories and composition and thickness of various protective coating systems necessary to ensure a short-term, mid-term or long-term anti-corrosion protection. However, solely categories $\mathrm{C} 1$ and $\mathrm{C} 2$ would be considered typical of the majority of coatings, when the film of intumescent coating is sufficiently thick. However, locally there may be such coating spots requiring taking additional protective measures from destructive environmental effects. Climate effects usually change the colour, facture, structure, chemical composition or shape of the affected objects (Stankevičius 1997).

In laboratories, finishing coatings are artificially aged in special chambers imitating processes occurring in the natural environment, when regulating the temperature, UV radiation, humidity and composition of gaseous pollutants. Accelerated research methods aimed at determining the behaviour of materials and components during their operation are much more aggressive than those occurring under natural conditions (Brunner et al. 2005).

Finding a significant correlation between the determined aging of coatings under laboratory and natural conditions is complex (Deflorian et al. 2007; Fedel et al. 2013). These researchers examined coatings in different regions, observing changes thereof for 10-12 months, and examined those same coatings in the laboratory. Additional exposure of materials to UV rays was determined to be insufficient simulating natural conditions, while the thickness of the coating due to water accumulation at the metal-coating interface may have the greatest impact. The research (Deflorian et al. 2008) revealed that urban environment with pollution may affect the surfaces more than the above-mentioned indicators. Researchers (Palm, Carlsson 2002) conducted research simulating the impact of acid rain on coatings. It was determined that in 30 years of natural aging under Italian climate conditions intumescent coatings no longer perform their function in practice (Bilotta et al. 2016).

Wang et al. (2014) examined the aging mechanism of intumescent fire protective coatings affected by acid corrosion. The conducted TG/DTG and SEM researches revealed that certain coating components, especially pigments, were lost due to the dissolution, acid catalysed hydrolysis and chemical reaction with the acid, which resulted in the deterioration of the fire resistance property. Meanwhile the changes in pigment proportions caused by the migration of the concentration gradient could also affect the fire resistance performance of the coating. When the coating surface and char layer morphology were concerned, after the acid erosion, the thickness of the coating thinned, the surface became rough and had cracks and broken holes. Mačiulaitis et al. (2012) in their work showed, that DTA testing provides a lot of information about the processes that occur, when the material is on fire. Particularly useful results are obtained on polymer coatings under a nitrogen environment.

Chinese scientists Zhang et al. (2014) drew up a mathematical model, which could be used for forecasting the longevity of intumescent fire protective coatings. But this is a preliminary forecasting only, assessing Chinese climate and using coatings of a certain composition and of two thicknesses only. Researchers admit that studies of different coatings and different coating thicknesses are necessary in order to assess the longevity of intumescent fire protective coatings more accurately.

Grigonis et al. (2012) examined the impact of the aging of intumescent fire protective coatings on their effectiveness. Coatings were aged under different regimes in the laboratory and under natural outdoor conditions under the roof. A strong relation (correlation coefficient 0.82 ) was received between the time of reaching critical temperature and aging cycles. An empirical equation was drawn up, illustrating that the time of reaching critical temperature decreases by about $50 \%$ calculating of the number of aging cycles. Also the article analyses the changes in the structure of coatings after 15, 30 and 60 aging cycles in the laboratory. The height of the resulting foam in the aged fire coatings decreased as soon as after 15 cycles by $19 \%$, and after 60 cycles it decreased by as many as $40 \%$ compared to the control samples.

However, the simulation of climatic longevity tests, their application and use for specific environments has not yet been examined sufficiently well. Results of accelerated aging of construction products in climatic test chambers have little to do with their longevity in nature, because very few studies with fire protective coatings were conducted. Also, there still is no uniform theory of aging of fire protective paint coatings under the impact of main climatic factors created. Fire protective coating should fully retain its thermal and mechanical properties and conduct its functions throughout the entire lifecycle of the building or the structure.

The aim of this work is to examine the peculiarities of the destructive mechanism of intumescent and combined fire protective paint coatings with their aging.

\section{Materials and methods}

Plates cut out of $1 \mathrm{~mm}$-thick steel plates with $(250 \pm 1) \mathrm{mm} \times$ $(200 \pm 1) \mathrm{mm}$ edges and mass ratio of $3600 \mathrm{~m}^{-1}$ were used in the tests. Dust was cleaned of the plates, then degreasing the plates using the preparation "SK 646". After the residues of the preparation evaporate from the plate surface, anticorrosive alkyd primer GF02 (hereinafter - AG), was sprayed on all sides of the plate. The yield of anticorrosion primer AG is $150 \mathrm{~g} / \mathrm{m}^{2}$ for the thickness of the dried layer to be $40-50 \mu \mathrm{m}$. Primed plates were placed in the drying chamber with drying temperature of $+25^{\circ} \mathrm{C} \pm$ $2{ }^{\circ} \mathrm{C}$. The plates were removed from the drying chamber in 
Table 1. Characteristics of intumescent fire protective coatings

\begin{tabular}{|clcccc|}
\hline $\begin{array}{c}\text { Specific mark of } \\
\text { intumescent coating }\end{array}$ & \multicolumn{1}{c}{ Basic binder } & $\begin{array}{c}\text { Density, } \\
\mathrm{kg} / \mathrm{l}\end{array}$ & $\begin{array}{c}\text { Amount of non-volatile } \\
\text { substances by wt, } \%\end{array}$ & $\begin{array}{c}\text { Volatile organic } \\
\text { compounds, g/l }\end{array}$ & $\begin{array}{c}\text { Solvent and/or } \\
\text { diluent }\end{array}$ \\
\hline STG50 & Acrylic styrene copolymer & 1.30 & $68 \pm 3$ & 325 & Xylene \\
STD05 & Polyvinyl acetate & 1.43 & $70 \pm 3$ & 30 & Water \\
THR01 & Polyvinyl acetate & 1.35 & $75 \pm 5$ & - & Water \\
ATM & Polyvinyl acetate & 1.40 & $65 \pm 5$ & - & Water \\
\hline
\end{tabular}

24 hours, visually inspected for occurred coating damage spots and kept in the conditioning room for 180 hours at the temperature of $+20^{\circ} \mathrm{C} \pm 2{ }^{\circ} \mathrm{C}$ and relative humidity of $65 \% \pm 5 \%$. After the conditioning period has passed, the average thickness of soil coating of each plate was measured in 24 points and then recorded. The thickness ranged from $40 \mu \mathrm{m}$ to $50 \mu \mathrm{m}$. The "Mega Check" device operating under magnetic induction principle was used to measure the thickness of the coatings according to the EN ISO 2178:2016 (2016) standard.

Four types of intumescent fire protective coatings were chosen for coating, including ATM, THR01 and STD05, the binders of all of which are polyvinyl acetate resins, and STG50, the binder whereof is acrylic styrene copolymer (more characteristics of coatings are presented in Table 1). One series of samples was covered in an additional protective (non-fire protective) paint coating acrylic resin-based ADD coating, and one - silicone resinbased SDD coating, which are generally considered to be the most resistant to climatic factors. plates.

Figure 1 illustrates the stages of preparation of the

Plates painted in intumescent fire protective paint were placed in the drying chamber with maintained temperature of $+25^{\circ} \mathrm{C} \pm 2{ }^{\circ} \mathrm{C}$; they were removed in 24 hours and stored in the conditioning room for 7 days. After such storage, the paint coating was fully hardened. The thickness of the coating measured by "Mega Check" device ranged from $980 \mu \mathrm{m}$ to $1050 \mu \mathrm{m}$. The coating and other operations with additional protective (non-fire protective) paint coatings were performed in the same sequence.

Intumescent fire protective coatings were artificially aged in two different regimes. A $122 \times 48 \times 72 \mathrm{~cm}$ (length $\times$ width $\times$ depth) calibrated freezing chamber Whirlpool AFG 543-C/H, a desiccator, a quartz lamp SUNLAMP 70UVA/B generating ultraviolet rays (power $-120 \mathrm{~W}$ ), sample conditioning room maintaining temperature of $+20{ }^{\circ} \mathrm{C} \pm 2{ }^{\circ} \mathrm{C}$ and relative air humidity $45 \% \pm 5 \%$ were used in the tests. Duration of one cycle was 24 hours. The second selected simulated test regime included: the volumetric freezing of samples for 6 hours in the fridge at the temperature of $-20^{\circ} \mathrm{C} \pm 2{ }^{\circ} \mathrm{C}$; one-sided irradiation of sample coating using a quartz lamp for 1 hour at the distance of 1 meter; volumetric heating of samples for 17 hours in the desiccator above water at the temperature of $+20^{\circ} \mathrm{C} \pm$ $2{ }^{\circ} \mathrm{C}$ and relative air humidity $-95 \% \pm 5 \%$. One cycle lasted for 24 hours. The natural test was implemented after storing samples for 12 months (starting from 1 October) under outdoor conditions under the roof (in the attic).

A vertical fire resistance test furnace meeting requirements of standards EN 1363-1 (2012) and EN 1363-2 (2000) was used to determine thermal properties of intumescent fire protective coatings, raising the temperature according to the standard fire curve.

The scanning electronic microscope JEOL JSM-7600F with resolution of $1.5 \mathrm{~nm}$ and magnification from 25 to

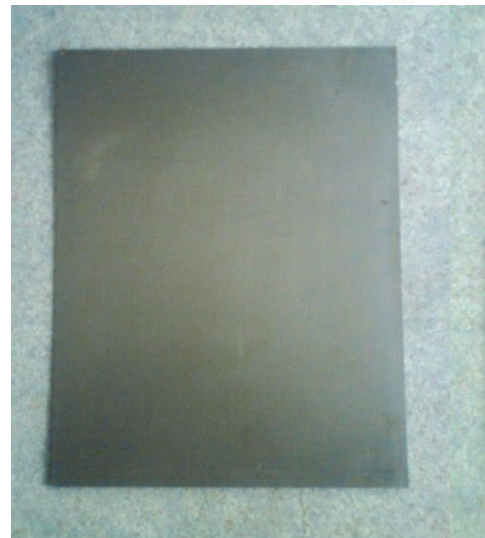

a)

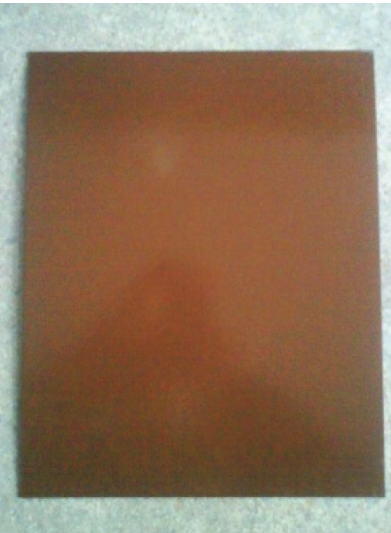

b)

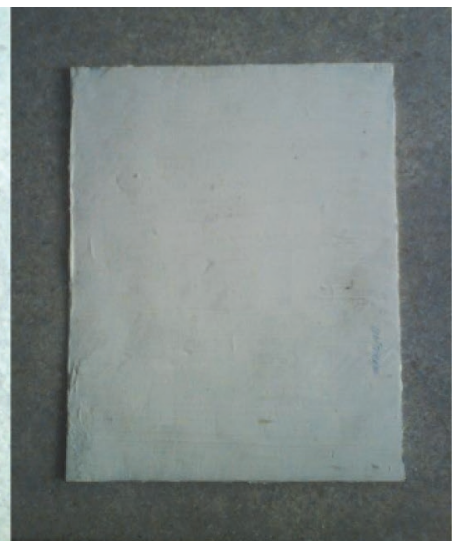

c)

Figure 1. Steel plates for the test preparation phases: a) clean steel plate; b) plate coated with primer; c) plate covered in polymeric intumescent fire protective coating 
1000000 times was used for the analysis of the structure of the surface of intumescent fire protective coatings; voltage of $4.0 \mathrm{kV}$ was used during the tests, covering the surface of the tested samples in gold. Derivatographers PT 1000 and Netzsch TG 209 F1 Libra coupled with FT-IR spectrometer were used to examine properties of the samples; data was processed according to instructions of EN ISO 113571:2010 (2010) and EN ISO 11358-1:2014 (2014) standards.

Chemical composition of intumescent fire protective coatings was examined in application of Fourier-transform molecular absorption micro-spectroscopy method in the infrared area of the spectrum (FT-IR micro- spectroscopy). FT-IR micro-spectroscopy of intumescent fire protective coatings is the method of research of chemical composition of intumescent fire protective coatings based on the examination of infrared radiation absorption spectra. Absorption spectra of intumescent fire protective coatings are registered using FT-IR spectrometer "Spectrum One" manufactured by PERKIN ELMER, and FT-IR microscope "AutoIMAGE".

The registered absorption spectra of intumescent fire protective coatings were analysed and compared assessing the characteristics of the registered spectra (the shape of the spectra, position and shape of absorption bands, relative distribution of intensity), determining chemical composition of paint components according to functional molecular groups corresponding to absorption bands - a binder, aggregates, pigments, etc. Intumescent fire protective coatings were identified and compared according to these features.

\section{Results and analysis}

Each fire protective coating has different thermal insulation properties, and differently responds to changes in temperature and moisture, which cause destruction effects in the composition of polymer coating. Thus sufficiently different fire resistance test results are received (Table 2).

The greatest differences were obtained when working with aged samples, which were not covered in additional protective coating. In these cases, worse results than in case of natural aging of samples for 12 months were obtained after 60 aging cycles. However, trends of the time for reaching critical temperature were similar, even though significantly lower. It was determined that after 12 months of natural aging, the resistance of intumescent fire protective coatings decreased from $8.2 \%$ to $35.1 \%$, meanwhile, the fire resistance after 60 artificial aging cycles according regime I decreased from $14.1 \%$ to $53.8 \%$, thus these coatings can be stated not to be long-lived, when they are affected by changes in temperature and moisture.

Figure 2 illustrates microstructures of control samples and samples after 12 months of aging with STG50 coating, the binder whereof is styrene acrylic copolymer. The surface of the dried coating of control intumescent fire protective paint coating samples was sufficiently even and had a few defects only (Figure 2a). After 12 months of aging (Figure $2 \mathrm{~b}$ ), substances, namely, precipitate, formed on STG50 surfaces were, which were absent on the dried (control) coating surface (1), with prevailing formed cavities, the diameter whereof ranged from $0.35 \mu \mathrm{m}$ to $0.8 \mu \mathrm{m}$ (2) as a result of the destruction process of the coating. Having magnified the image (Figure 2c), a space of $1.3 \mu \mathrm{m}$ it is seen in the middle of new formations. New formations seen on its edges are likely to have been washed from coating cavities and treated as materials (precipitate) released from surface layers as a result of destruction processes.

Defects of a different nature dominated the surface of fire protective paint coating STG50 with ADD, which was determined by the protective coating layer in particular. A number of damage spots of different nature was observed on the surface after 12 months of aging (1): cracks, flaking, and delamination (Figure 2d).

Using additional SDD coating to protect fire protective paint coating STG50 (Figure 2e), extensive destruction of the surface of the protective coating - cracks - were observed (1). Also, a grid of deeper cracks has formed on the surface, with the width of damage reaching up to $5 \mu \mathrm{m}$ in certain places. This allows judging that the additional protective coating is significantly disintegrated, having lost its protective function.

Figure 3 illustrates microstructures of control samples and samples after aging with STD05 coating with polyvinyl acetate resin as its binder. The surface of intumescent fire protective paint coating STD05 is also sufficiently even with a few defects only (Figure 3a). Coatings of primers

Table 2. Fire resistance decrease of different intumescent coatings after aging (critical temperature $500{ }^{\circ} \mathrm{C}$ )

\begin{tabular}{|c|c|c|c|c|}
\hline $\begin{array}{l}\text { Intumescent } \\
\text { coating }\end{array}$ & Soil & $\begin{array}{l}\text { Additional protective } \\
\text { non-fire protection coating }\end{array}$ & $\begin{array}{l}\text { Decrease of fire resistance, \% } \\
\text { after } 60 \text { aging cycles }\end{array}$ & $\begin{array}{l}\text { Decrease of fire resistance, } \% \text { after } 12 \\
\text { month aging under outdoor conditions }\end{array}$ \\
\hline \multirow{3}{*}{ STD05 } & \multirow{3}{*}{ AG } & - & 32.5 & 29.4 \\
\hline & & $\mathrm{ADD}$ & 14.1 & 8.2 \\
\hline & & SDD & 23.7 & 13.6 \\
\hline \multirow{3}{*}{ STG50 } & \multirow{3}{*}{ AG } & - & 53.8 & 32.5 \\
\hline & & $\mathrm{ADD}$ & 25.6 & 19.8 \\
\hline & & SDD & 26.0 & 18.0 \\
\hline \multirow{2}{*}{ THR01 } & \multirow{2}{*}{ AG } & - & 40.5 & 35.1 \\
\hline & & SDD & 25.2 & 16.5 \\
\hline
\end{tabular}


a)

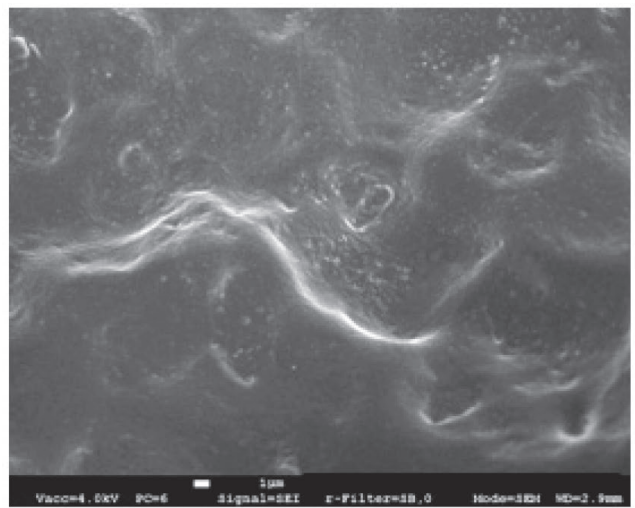

c)

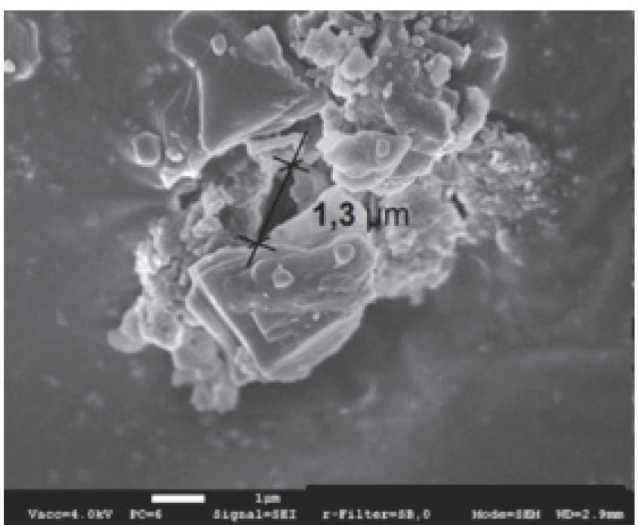

b)

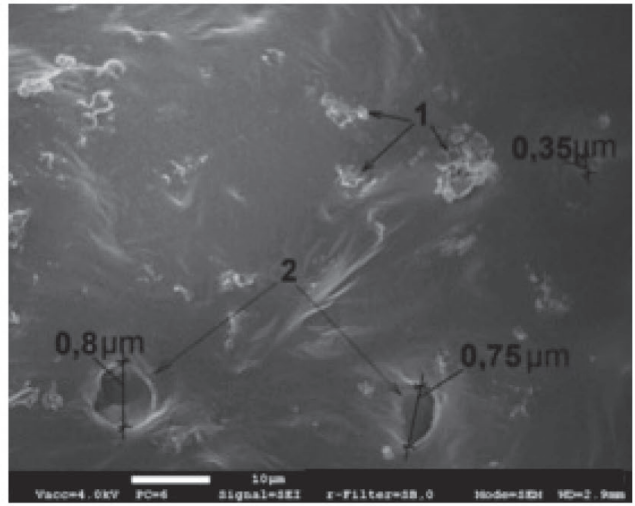

d)

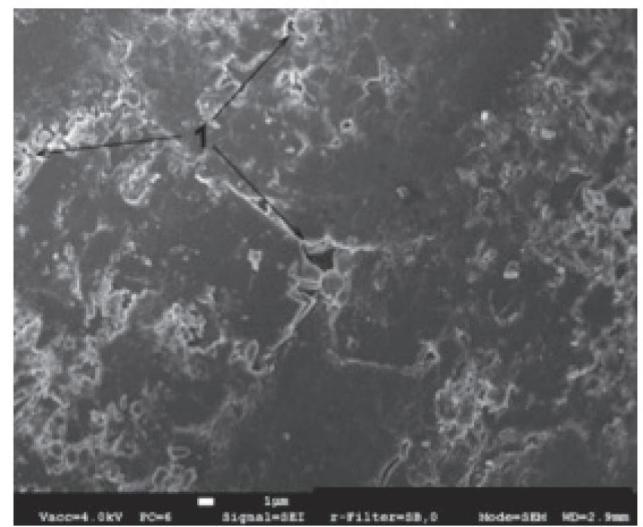

e)

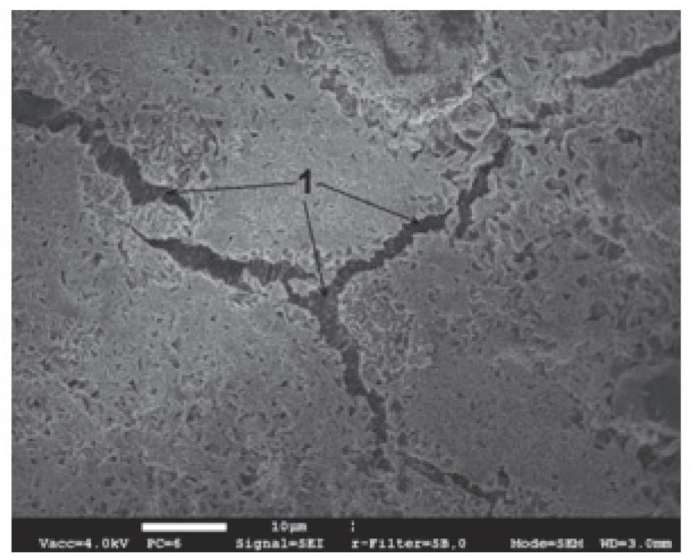

Figure 2. Images of microstructure of samples with STG50 paint coating: $\mathrm{a}$ - dry paint coating surface; $\mathrm{b}$ - paint coating surface after 12 months of natural aging: 1 - precipitate, 2 - cavity; c - paint coating surface after 12 months of natural aging, cavity formed in and around the precipitate; $\mathrm{d}$ - paint +ADD coating surface after 12 months of natural aging: 1 - cracks, delamination; e - paint + SDD coating surface after 12 months of natural aging: 1 - pavement cracks a)

and paint obviously make up a specific system of pores and capillaries. Changes were observed on the surface of "STD05"' paint coating after 15 aging cycles under regime I (Figure 3b): cavities (1) and precipitate (3) have formed.

More damages $(1,2)$ and precipitate (3) were observed on the surface of identical samples after 30 aging cycles compared to 15 aging cycles. Micro-cracks, $1.6 \mu \mathrm{m}$ cavities and new formations were observed on the surface (Figure 3c).

A significant development of cavities (1) and an increasing amount of precipitate (3) was observed in samples after 45 artificial aging cycles (Figure 3d). Surface of identical samples formed after 60 artificial aging cycles under regime I, with the formation of an even greater number of cavities, the diameter whereof reached up to $7 \mu \mathrm{m}(1)$, and an even greater amount of new formations (Figure 3e).

In the performance of aging tests, damage to the volume and surface of primers and paint coatings comes as a result of atmospheric humidity and change of temperatures. Having removed frozen samples from the freezing chamber and placed them in the desiccant for thawing, moisture contained in the air condenses on the paint coat- 
a)

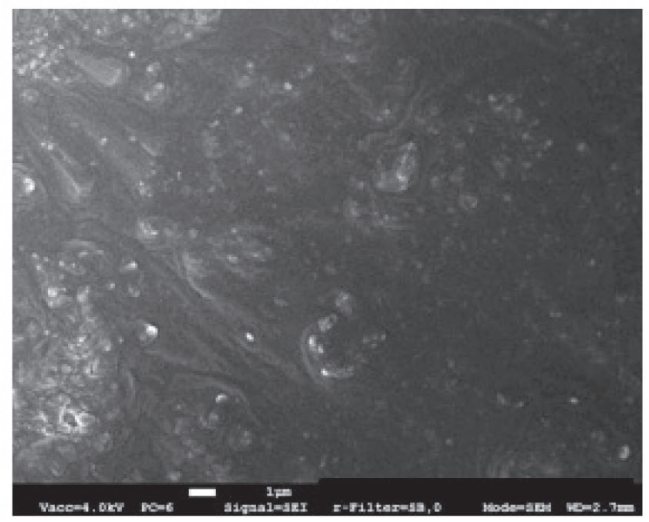

b)

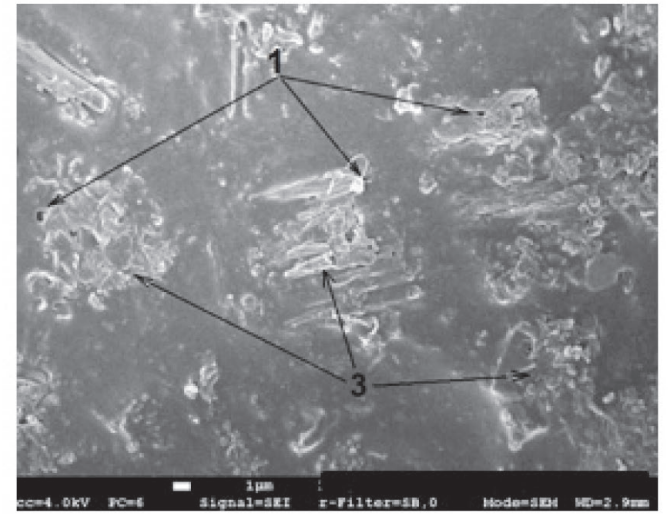

d)

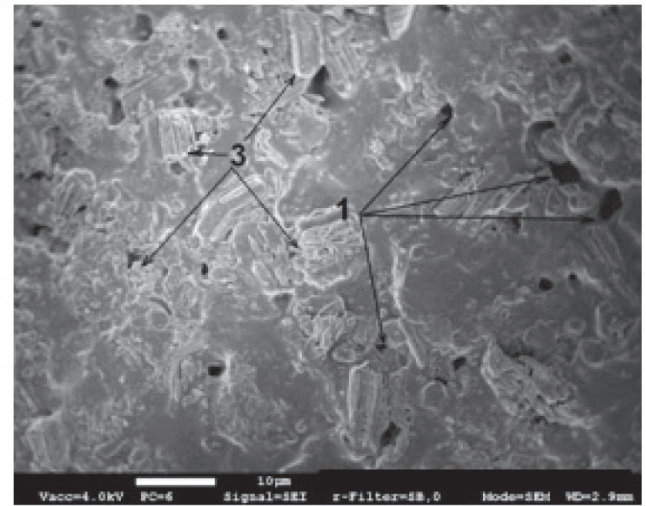

c)

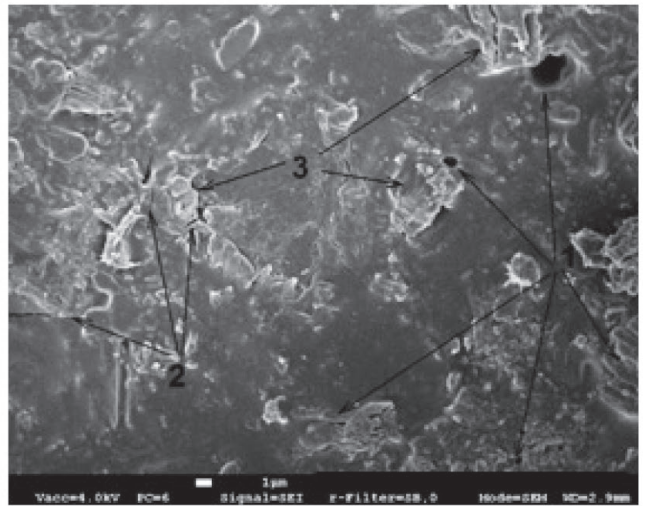

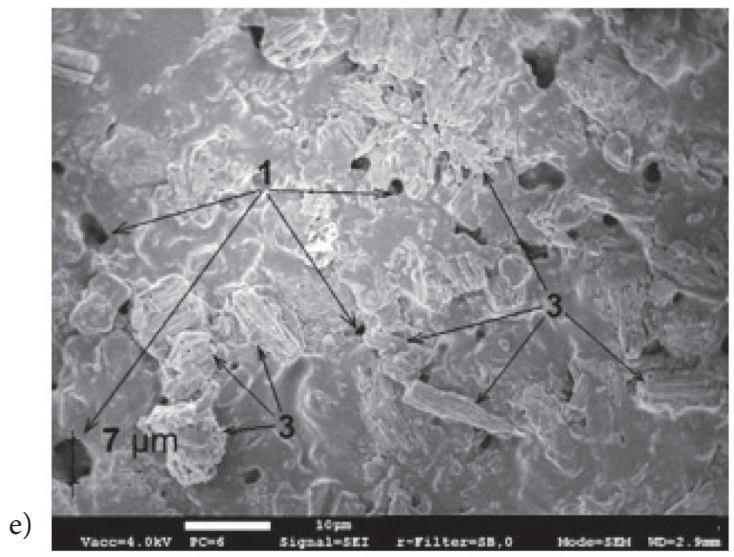

Figure 3. Images of microstructure of samples with STD05 paint coating: a - dry paint coating surface; $b$ - paint coating surface after 15 cycles of treatment under I regime: 1 - cavity, 3 - precipitate; c - paint coating surface after 30 cycles of treatment under I regime: 1 - cavity, 2 - cracks, 3 - precipitate; $\mathrm{d}$ - paint coating surface after 45 cycles of treatment under I regime: 1 - cracks, 3 - precipitate; e - paint surface after 60 cycles of treatment under I regime: 1 - cavity, 3 - precipitate

ing surface, because the dew point forms on the surface of a steel plate. After the sample thaws, the water also soaks the coating and later migrates to inner layers of the coating, where water-soluble or dilutable coating components gradually dissolve or disperse. Literature reveals that ammonium polyphosphate, pentaerythritol, melamine and other components of such paints are more or less soluble in water and interacting therewith. Components of intumescent fire protective coatings, such as mono ammonium phosphate compounds, come out of the coating in contact with water (Hill 1993).
Having placed the sample back in the freezing chamber for refreezing, water having penetrated micro-pores and capillaries that formed in the coating during soaking freezes therein, leading to the development of overpressure and gradual destruction of the coating structure due to the expansion of crystalizing water and further water migration processes. A part of the water solution migrates to the surface of the coating, the sublimation dries out, while the dissolved components re-crystalize and/or re-amorphise, thus resulting in the formation of cavities and crystals or amorphous precipitate around them. This is also con- 


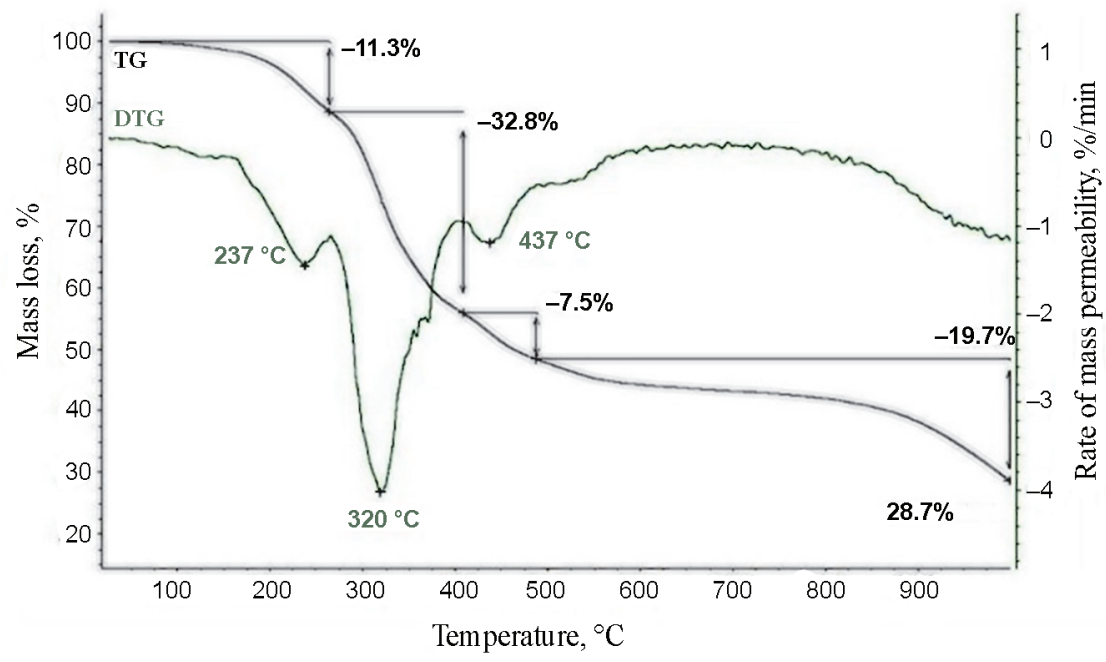

Figure 4. TG, DTG curves fire intumescent paint ATM under nitrogen

firmed by the fact that with the increasing number of aging cycles, increasingly larger cavities appear, a network of cracks forms and the precipitate amount increases. Paint components soaking and soluble in water, which accumulate on the coating surface, can potentially react with, and say $\mathrm{CO}_{2}$ contained in the air, forming carbonate crystals, or react with other air components.

Similar heat and mass exchange and destruction processes were also observed in ceramic bricks and blocks, which have pore and capillary systems, and take place when determining product resistance to frost in the masonry by way of a one-way cyclic refrigeration - thawing under operating conditions (Mačiulaitis 1997).

In our case, the same effect was also reached when aging paint coatings for 12 months under the effect of the key natural factors. Thus precipitate on coating surfaces forms due to the mass and heat exchange processes, when paint components interacting with water, diluting therein and regulating the formation of intumescent coating are washed to the surface (especially due to poor distribution or insufficient dispersion in paint coatings). This is how cavities, cracks and fractures form in coatings, and they no longer perform their main function. Finally, increasing the number of artificial or natural cycles, the surface of the coating is destroyed in essence, precipitate is washed out and the thickness of the forming foam and, in turn, fire resistance decreases during burning. Of course when components are distributed in paint and their coating more evenly, and when burning unaged intumescent fire protective paint coating, the necessary fire resistance is ensured. Moreover, the smell of ammonia was felt organoleptically at the time of aging of certain paint during tests, which could imply, say, chemical destruction of melamine or ammonium polyphosphate.

Having conducted thermogravimetric research with ATM intumescent fire protective coating, the binder whereof is polyvinyl acetate resin, four mass loss stages $(11.3 \%, 32.8 \%, 7.5 \%$ and $19.7 \%)$ can clearly be seen in the thermogram (Figure 4), which reached minimums at the temperatures of $237^{\circ} \mathrm{C}, 320^{\circ} \mathrm{C}, 437^{\circ} \mathrm{C}$ and $990{ }^{\circ} \mathrm{C} .11 .3 \%$ of mass was lost in the first stage, including the absorbed water of the coating, when the temperature changed from $20{ }^{\circ} \mathrm{C}$ to $270{ }^{\circ} \mathrm{C}$. The greatest mass loss of $32.8 \%$ was captured during the second loss of mass, when the temperature changed from $270{ }^{\circ} \mathrm{C}$ to $425^{\circ} \mathrm{C}$. Mass loss accounted for $7.5 \%$ in the third stage at the temperature of $425^{\circ} \mathrm{C}$ $480{ }^{\circ} \mathrm{C}$. In the fourth stage at temperatures of $480{ }^{\circ} \mathrm{C}-$ $990{ }^{\circ} \mathrm{C}$, the loss of mass accounted for $19.7 \%$, which was likely dominated by the carbonization process (Figure 4). These stages are disintegration of components of paint coatings at a certain temperature and their burning (oxidation). The residual mass at the end of the experiment accounted for $28.7 \%$; inorganic salts (ash) and coke residues should theoretically form its base.

Foaming paint additives are inorganic and organic; they increase fire resistance, including flame retardants, using urea, zinc carbonate, boric acid, ammonium polyphosphate, melamine, pentaerythritol and a number of other compounds therefor (copolymers of melamine and pentaerythritol, chlorinated paraffin, trichlorethyl phosphate) (Andersson et al. 2007; Jimenez et al. 2006; Li et al. 2007; Knunjanc 2000; Chemistry Encyclopedia 2015).

Thermograms of intumescent fire protective coating THR01, the binder whereof is polyvinyl acetate resin as well, (Figures 5a, 5b and 5c) clearly illustrate mass loss stages. The comparison of DTA curves in the said figures allows stating that artificial aging cycles under regimes I and II had an impact on changes in composition of intumescent fire protective coatings.

Six endothermic effects dominate the DTA curve of unaged intumescent fire protective coating THR01 at temperatures $71.7^{\circ} \mathrm{C}, 118^{\circ} \mathrm{C}, 185.5^{\circ} \mathrm{C}, 230.6{ }^{\circ} \mathrm{C}, 310^{\circ} \mathrm{C}$ and $322^{\circ} \mathrm{C}$, the peak minima whereof is sufficiently high (Figure 5a). It is important to note that heat is consumed in the course of those processes, at the same time capturing mass losses and the formation of a thermal insulating coating. The first end effect reached at $\sim 72{ }^{\circ} \mathrm{C}$ and the second end effect, the minimum whereof manifested at $\sim 118^{\circ} \mathrm{C}$, can 

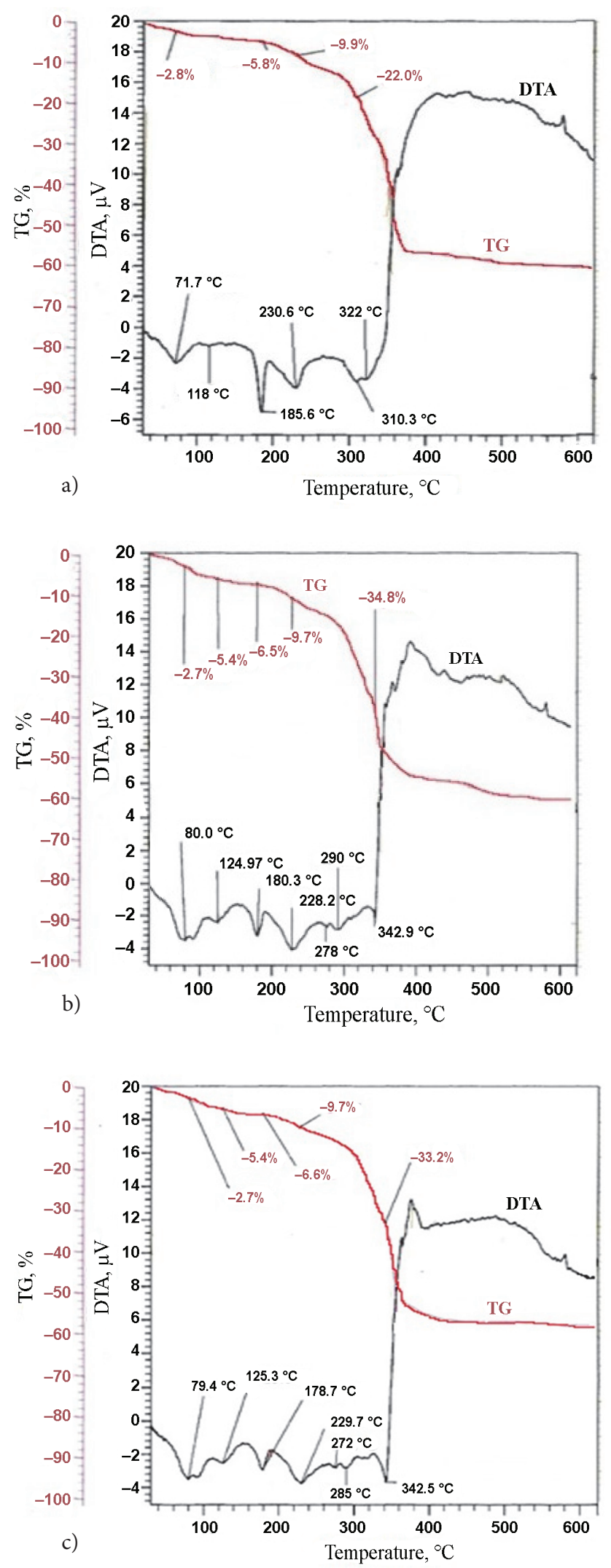

Figure 5. Intumescent fire protective coating THR01 thermograms: a - TG and DTA curves unaged fire coating tested nitrogen; $\mathrm{b}$ - TG and DTA curves of fire aged under 60 cycles according to regime I treatment coatings tested nitrogen; c - TG and DTA curves aged 60 cycles according to regime II treatment pursuant to the fire coating tested nitrogen be explained by the removal of water in pores and capillaries from the coating physically or physico-chemically bound in its porous system taking place during the analysis.

The four following endo effects are likely to take place due to the destruction of components foaming coatings, for the occurrence of which heat is consumed. Since paint manufacturers do not disclose the composition of components of their products, except for a polymer binder, diluent and several other technical indicators, only a guestimate can be made on which components serve as coating foamers (flame retardants, monomers or gaseous fuels). Moreover, scientific literature also often refers to different disintegration temperatures of identical compounds.

The third end effect is likely to be explained by disintegration of zinc carbonate or boric acid having reached the temperature of $185.5^{\circ} \mathrm{C}$. The fourth end effect may be explained by disintegration of ammonium polyphosphate or melamine at the temperature of $230.6{ }^{\circ} \mathrm{C}$. The fifth end effect can be explained by disintegration of melamine or pentaerythritol having reached the temperature of $310.3{ }^{\circ} \mathrm{C}$. The sixth end effect may be explained by the disintegration of new formations of melamine or pentaerythritol at the temperature of $322^{\circ} \mathrm{C}$.

With further temperature rise, the DTA curve allows stating that the oxidation process starts accompanied by a high heat release (exogenous effect) and high mass losses at the time of which atomic oxygen contained in compounds is used (Mačiulaitis et al. 2012).

Thermal analysis of coating THR01 aged according to regime I for 60 cycles showed that the localization of endothermic effects changed (Figure $5 \mathrm{~b}$ ). The first end effect converted to duplex at $80^{\circ} \mathrm{C}$ and $90{ }^{\circ} \mathrm{C}$ with a $+18{ }^{\circ} \mathrm{C}$ temperature shift. The second end effect, the minimum whereof manifests at the temperature of $124.9^{\circ} \mathrm{C}$, also associated with water removal from coating shifted by $+7^{\circ} \mathrm{C}$. Having compared the temperature shift of the third end effect to that of unaged coating from $185.6^{\circ} \mathrm{C}$, with the temperature shift of $180.3^{\circ} \mathrm{C}$, the result of $5.3^{\circ} \mathrm{C}$ was achieved. This also applies to the fourth end effect, the peak whereof manifested at $229.7^{\circ} \mathrm{C}$, while the temperature change is quite obvious at $+2.4{ }^{\circ} \mathrm{C}$, solely in temperature rise direction having compared it to unaged THR01 coating. There is no doubt that the fifth and the sixth end effect starts in unaged THR01 coating in tests in nitrogen having reached the temperature of $310.3^{\circ} \mathrm{C}$, while the following sixth end effect manifests at $322.0^{\circ} \mathrm{C}$ (Figure 5a). A rather sharp duplex has been observed in THR01 coating aged under regime I having reached $278.0^{\circ} \mathrm{C}$ and $290.0^{\circ} \mathrm{C}$ with a maximum temperature shift of $32^{\circ} \mathrm{C}$. In case of the sixth end effect, having reached the temperature of $342.9^{\circ} \mathrm{C}$, the shift is of an opposite direction and totals $+21^{\circ} \mathrm{C}$. This is when a regular oxidation process starts accompanied by a significant heat release (Figure $5 b$ ), at the time of which elemental oxygen of disintegrating compounds is used (Mačiulaitis et al. 2012).

Important changes were also observed in THR01 coating aged according to regime II. The changes of the first and second end effect are practically the same for coat- 
Table 3. Various intumescent fire protective coating mass losses under nitrogen at heating up to $600{ }^{\circ} \mathrm{C}$

\begin{tabular}{|cccc|}
\hline \multirow{2}{*}{$\begin{array}{c}\text { Name of polymeric intumescent } \\
\text { fire protective paint coating }\end{array}$} & Control & Aged according to regime I & Aged according to regime II \\
\hline THR01 & 47.17 & 57.90 & 58.88 \\
\hline STD05 & 47.34 & 51.77 & 52.73 \\
\hline STG50 & 54.95 & 60.38 & 63.63 \\
\hline
\end{tabular}

ings aged under regime I. Compared to unaged coating, at the temperature of $185.6{ }^{\circ} \mathrm{C}$ (Figure 5a), the temperature shift of the third end effect is obtained with a significant temperature shift at $178.7^{\circ} \mathrm{C}$ (Figure $5 \mathrm{c}$ ) equal to $-6.9^{\circ} \mathrm{C}$. The temperature shift is rather small and negative $\left(0.9^{\circ} \mathrm{C}\right)$ in the fourth end effect, in the THR01 coating aged under regime II having reached the temperature of $229.7^{\circ} \mathrm{C}$, compared to the control sample at $230.6{ }^{\circ} \mathrm{C}$ (Figure 5a). In the THR01 coating aged under regime II, the fifth duplex manifests having reached $272.0^{\circ} \mathrm{C}$ and $285.0^{\circ} \mathrm{C}$ with the maximum temperature shift of $38^{\circ} \mathrm{C}$ and the sixth - at the temperature of $342.5^{\circ} \mathrm{C}$ with the maximum temperature shift of $+20.5^{\circ} \mathrm{C}$. This is when the regular oxidation process accompanied by a significant heat discharge starts (Figure 5c). This would mean that UV radiation destructs the fire protective coating more intensively together with relative humidity increased to the maximum.

From a different perspective, all this shows that very complex qualitative and quantitative chemical destruction processes take place during aging, but reaction of the formation of new formations cannot be rejected either (Wang et al. 2007).

Having conducted thermographic research with intumescent fire coatings THR01, STD05 and STG50, the identified total mass loss up to $600^{\circ} \mathrm{C}$ is presented in Table 3. Results of the thermographic analysis showed obvious differences between unaged and artificially aged coatings. This research reconfirmed the fact that fire protective paint coatings lose their thermal insulation properties with time, leading to decreased time of fire resistance.

Losses of sample mass reveal that the greatest mass losses were found in samples aged for 60 cycles under regime II, however, compared with the samples aged under regime I, the difference compared to those aged according to regime I ranges from $0.98 \%$ to $3.25 \%$, which shows that artificial aging modes had a sufficiently strong impact on fire resistance of coatings. However, the impact of regime II was more intense than destructive effects of regime I.

Thermal FT-IR analysis of THR01 unaged coating was conducted during the test (Figure 6). Various gases were released from the coating during the test. Gas was intensively released from the coating after the temperature started rising during the test and reached $200^{\circ} \mathrm{C}$. This lasted till the coating temperature reached $450^{\circ} \mathrm{C}$. This is also when the greatest mass losses occurred.

Gas and vapours released in the course of burning of intumescent fire protective and combined paint coatings are dangerous to human life, except for $\mathrm{H}_{2} \mathrm{O}$ (Žukas et al.

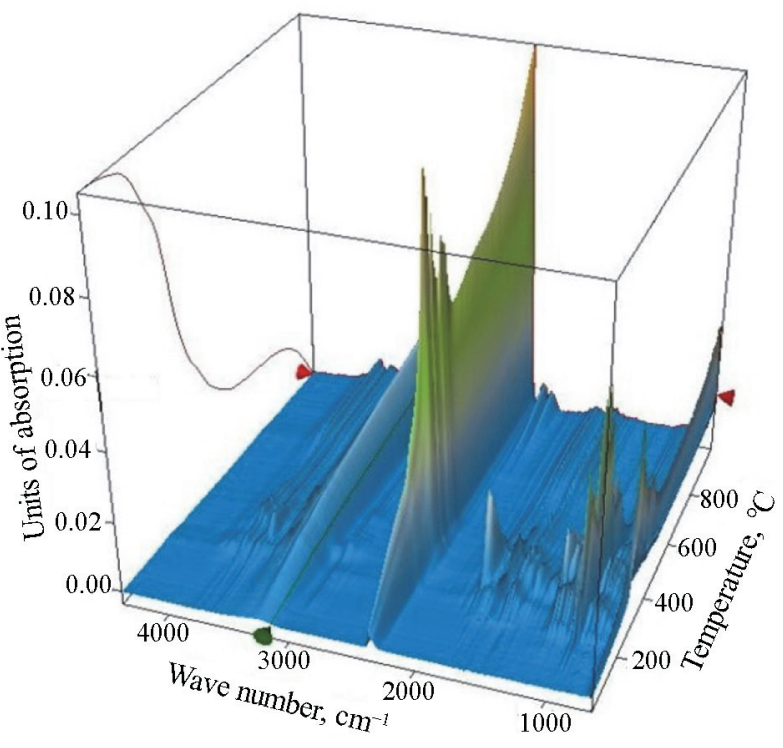

Figure 6. 3D view of all detected infrared spectra obtained by gas leaking from THR01 thermal analysis, surface temperature variations

2007; Darginavičienė, Drungilienė 2008). Chemical composition of dry intumescent fire protective paint coatings THR01, STD05 and STG50 was determined according to IR spectra.

According to Buika et al. (2007) wide medium and high intensity absorption peaks in the $3650 \div 3200 \mathrm{~cm}^{-1}$ spectrum indicate the presence of $\mathrm{OH}$ or $\mathrm{NH}$ connections. The presence of $2700 \div 2000 \mathrm{~cm}^{-1}$ wide absorption bands indicates the presence of $\mathrm{NH}$ groups. $3000 \div 2700 \mathrm{~cm}^{-1}$ peaks correspond to curvature $\mathrm{C}-\mathrm{H}$ tie vibrations in $\mathrm{CH}$, $\mathrm{CH}_{2}$ and $\mathrm{CH}_{3}$ groups. The intensity of these peaks may be an indicative indicator showing the content of these groups in the compound at the $1600 \div 1500 \mathrm{~cm}^{-1}$ wave. The presence of bands of much lower absorption in the $1200 \div 1000 \mathrm{~cm}^{-1}$ field area identifies $\mathrm{C}=\mathrm{C}, \mathrm{C}=\mathrm{N}$ or $\mathrm{NH}_{2}$, $\mathrm{NH}$ vibrations (Buika et al. 2007). This area is a part of "fingerprints" area, and this is the only absorption peak, which can be individually identified in $1000 \div 635 \mathrm{~cm}^{-1}$. Since IR spectrum is very complex, there is no universal methodology for its interpretation (Buika et al. 2007).

Spectra of dried coatings were chosen as control coatings, and they were compared with the coatings received aging the samples for 60 cycles under regime I and regime II. To be able to identify material changes, the number of waves of melamine (hereinafter - MEL), ammonium 
Table 4. The number of waves of intumescent fire protective coatings by the main components

\begin{tabular}{|c|c|c|c|c|c|c|c|c|c|c|c|}
\hline \multirow{3}{*}{$\begin{array}{c}\text { Material } \\
\text { APP }\end{array}$} & \multicolumn{11}{|c|}{ Number of waves, $\mathrm{cm}^{-1}$} \\
\hline & 3729 & 3215 & 3062 & 1776 & 1702 & 1444 & 1254 & 1138 & 1070 & 1024 & 896 \\
\hline & 800 & 762 & 682 & 646 & - & - & - & - & - & - & - \\
\hline MEL & 3348 & 2956 & 1559 & 1506 & 1358 & 1164 & 1116 & 1014 & 898 & 813 & 743 \\
\hline \multirow{2}{*}{ PEN } & 3342 & 2956 & 2887 & 2799 & 2652 & 2529 & 2049 & 1476 & 1452 & 1408 & 1383 \\
\hline & 1277 & 1231 & 1130 & 1208 & 1008 & 874 & 667 & - & - & - & - \\
\hline
\end{tabular}

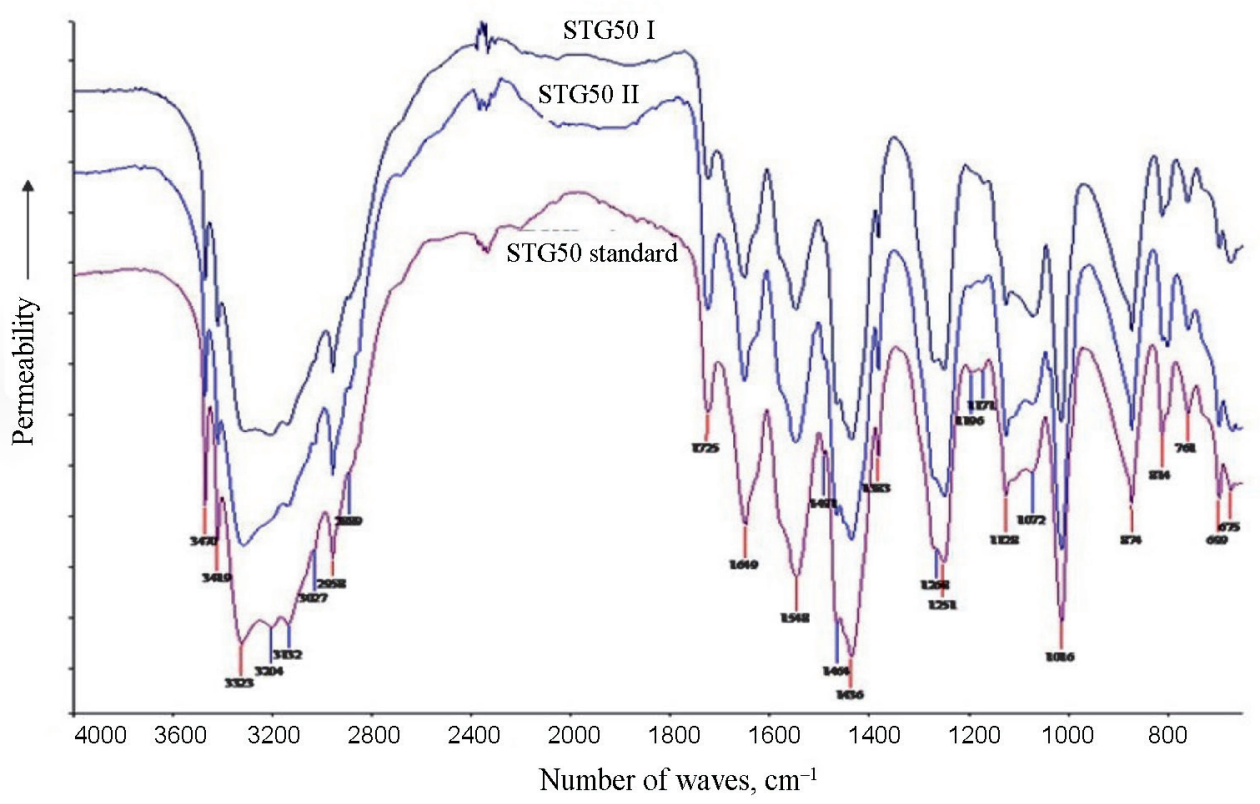

Figure 7. Intumescent fire protective coating STG50 samples of FT-IR spectra: STG50 standard - control samples, STG50 I - the coating was aged by I regime, STG50 II - aged by II regime

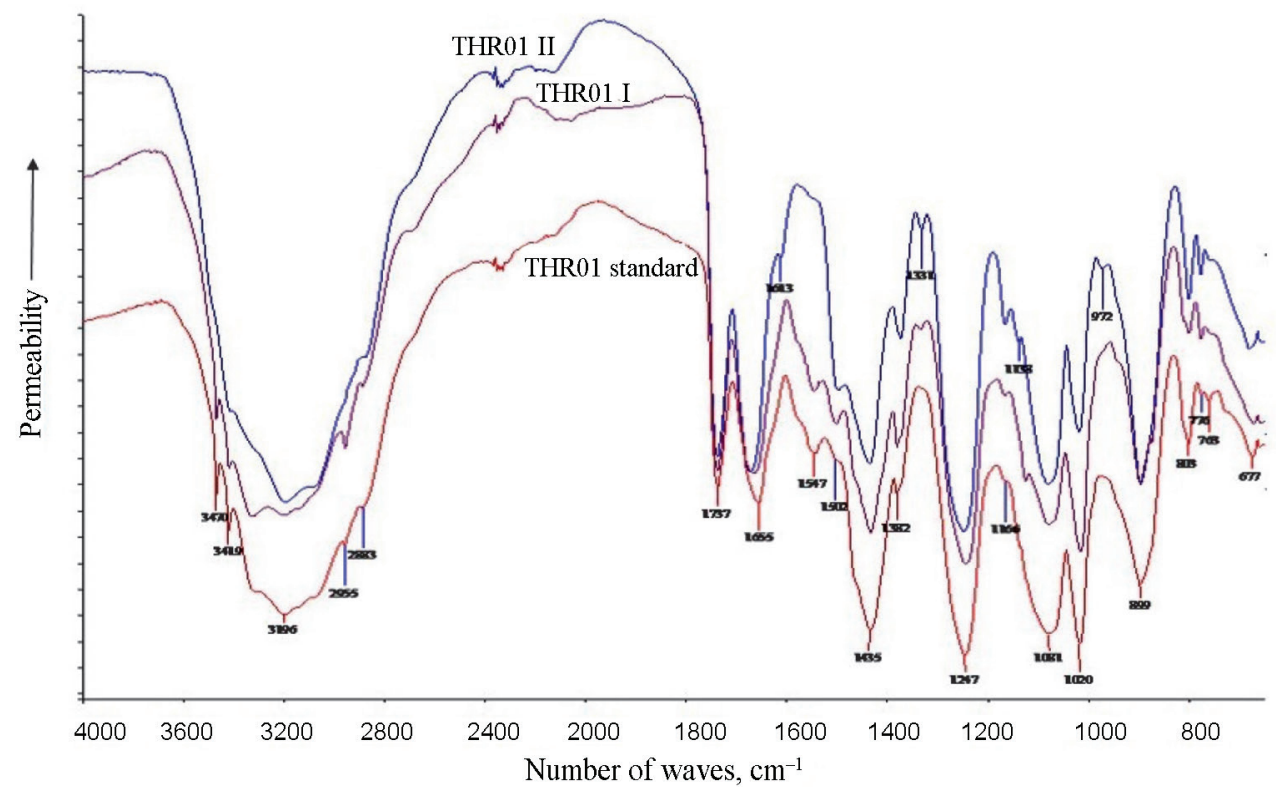

Figure 8. Intumescent fire protective coating THR01 samples of FT-IR spectra:

THR01 standard - control samples, THR01 I - the coating was aged by I regime,

THR01 II - aged by II regime 
polyphosphate (hereinafter - APP) and pentaerythritol (hereinafter - PEN) were registered and are presented in Table 4.

Figure 7 illustrates the number of waves recorded having conducted FT-IR tests with samples covered in intumescent fire protective coating STG50.

The comparison of the extremes of control sample with samples aged under different regimes I and II revealed that the intensity of sizes of several extremes decreases $\left(3348 \mathrm{~cm}^{-1}, 1559 \mathrm{~cm}^{-1}, 1164 \mathrm{~cm}^{-1}, 813 \mathrm{~cm}^{-1}\right)$. All these extremes belong to the melamine compound, thus changes in the molecular structure of melamine can be said to have taken place.

The greatest changes were observed in spectra of intumescent fire protective paint coatings THR01 and STD05, the polymer binders of which are dispersed in water. Figure 8 illustrates spectra of THR01 coating, revealing that after 60 cycles of artificial aging under regime I, the intensity of peaks decreased to $3470 \mathrm{~cm}^{-1}, 3419 \mathrm{~cm}^{-1}$, $3196 \mathrm{~cm}^{-1}, 1547 \mathrm{~cm}^{-1}, 1435 \mathrm{~cm}^{-1}, 803 \mathrm{~cm}^{-1}$ and $677 \mathrm{~cm}^{-1}$, leading to the formation of new peaks $1331 \mathrm{~cm}^{-1}$ and $1166 \mathrm{~cm}^{-1}$. After 60 cycles of artificial aging under regime II, the peaks $3470 \mathrm{~cm}^{-1}, 3419 \mathrm{~cm}^{-1}, 2955 \mathrm{~cm}^{-1}, 1613 \mathrm{~cm}^{-1}$ and $1547 \mathrm{~cm}^{-1}$ disappeared. Vibrations identifying the ties decreased, mainly in melamine and pentaerythritol, thus changes can be stated to have occurred in these components.

Having conducted the research of coatings aged under both regimes and unaged (control) coatings, the number of peaks reflecting the ties obviously decreased the most with the samples aged for 60 cycles under regime II (Table 5).

For example, peaks identifying $\mathrm{NH}_{2}$ group vibrations disappear $\left(813 \mathrm{~cm}^{-1}, 814 \mathrm{~cm}^{-1}, 1543 \mathrm{~cm}^{-1}\right.$ and $\left.1547 \mathrm{~cm}^{-1}\right)$, thus melamine compound can be stated to have already changed, while its absence also proves a lower height of the forming thermal insulation foam at high temperatures. Also, the identified new ties $\left(1334 \mathrm{~cm}^{-1}, 1127 \mathrm{~cm}^{-1}\right.$, etc.) and FT-IR microscopy analysis confirmed the fact that intumescent fire protective coatings are not very resistant

Table 5. Intumescent fire protective coatings THR01, STD05 and STG50 frequencies characteristic

\begin{tabular}{|c|c|c|c|c|c|c|c|c|c|c|c|c|c|}
\hline \multirow[b]{2}{*}{ 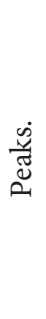 } & \multicolumn{13}{|c|}{ Number of waves, $\mathrm{cm}^{-1}$} \\
\hline & 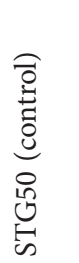 & 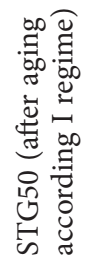 & 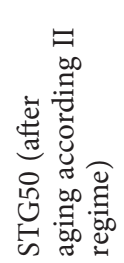 & 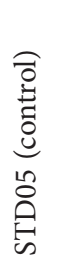 & 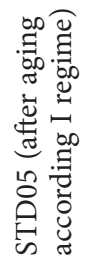 & 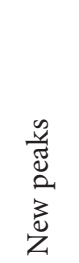 & 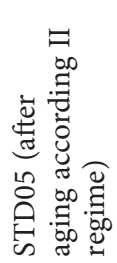 & 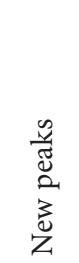 & 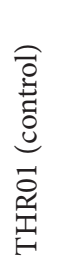 & 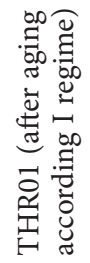 & $\begin{array}{l}\frac{n}{0} \\
\tilde{\Xi} \\
a \\
z \\
\tilde{z} \\
z\end{array}$ & 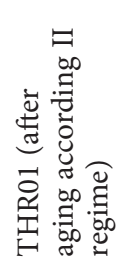 & 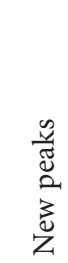 \\
\hline 1 & 3470 & 3470 & 3470 & 3696 & 3696 & - & 3695 & - & 3470 & 3470 & - & $\mathrm{x}$ & - \\
\hline 2 & 3419 & 3419 & 3419 & 3621 & 3621 & - & 3620 & 3651 & 3419 & 3414 & - & $\mathrm{x}$ & - \\
\hline 3 & 3323 & 3309 & 3316 & 3470 & 3470 & - & $\mathrm{x}$ & - & 3314 & 3324 & - & $\mathrm{x}$ & - \\
\hline 4 & 3198 & 3207 & 3132 & 3420 & 3419 & - & $\mathrm{x}$ & - & 3196 & 3193 & - & 3191 & - \\
\hline 5 & 3132 & 3132 & 3027 & 3199 & 3206 & - & 3200 & - & 3077 & 3077 & - & 3077 & - \\
\hline 6 & 2958 & 2957 & 2958 & 3138 & 3137 & 3077 & $\mathrm{x}$ & 3076 & 2955 & 2957 & - & $\mathrm{x}$ & - \\
\hline 7 & 2889 & 2889 & 2889 & 2955 & 2958 & - & 2955 & - & 2883 & 2883 & - & 2878 & - \\
\hline 8 & 1725 & 1724 & 1726 & 2889 & 2883 & - & 2889 & - & 1737 & 1738 & - & 1738 & - \\
\hline 9 & 1649 & 1650 & 1652 & 1739 & 1739 & - & 1736 & - & 1655 & 1664 & - & 1673 & 1610 \\
\hline 10 & 1548 & 1549 & 1549 & 1655 & 1658 & - & 1675 & 1613 & 1547 & 1547 & - & $\mathrm{x}$ & - \\
\hline 11 & 1491 & 1489 & 1491 & 1549 & 1543 & - & $\mathrm{x}$ & 1500 & 1500 & 1502 & - & 1497 & - \\
\hline 12 & 1464 & 1464 & 1467 & 1436 & 1436 & - & 1444 & - & 1435 & 1434 & - & 1437 & - \\
\hline 13 & 1436 & 1436 & 1436 & 1382 & 1382 & - & 1376 & 1333 & 1382 & 1382 & - & 1375 & - \\
\hline 14 & 1383 & 1383 & 1383 & 1248 & 1249 & - & 1249 & - & 1247 & 1246 & 1334 & 1250 & 1334 \\
\hline 15 & 1271 & 1271 & 1271 & 1168 & 1168 & - & 1168 & - & 1166 & 1168 & 1127 & 1168 & 1138 \\
\hline 16 & 1251 & 1251 & 1250 & 1068 & 1069 & - & 1084 & - & 1081 & 1082 & - & 1082 & - \\
\hline 17 & 1196 & 1197 & 1199 & 1020 & 1017 & - & 1022 & - & 1020 & 1018 & - & 1021 & 972 \\
\hline 18 & 1171 & 1171 & 1174 & 897 & 896 & - & 899 & - & 899 & 899 & 873 & 898 & - \\
\hline 19 & 1128 & 1127 & 1127 & 876 & 873 & - & $\mathrm{x}$ & - & 814 & 813 & - & $\mathrm{x}$ & - \\
\hline 20 & 1072 & 1072 & 1072 & 814 & $\mathrm{x}$ & - & $\mathrm{x}$ & - & 803 & 802 & - & 802 & - \\
\hline 21 & 1016 & 1016 & 1015 & 803 & 803 & - & 802 & - & 776 & 778 & - & 779 & - \\
\hline 22 & 874 & 874 & 874 & 762 & 760 & 779 & $\mathrm{x}$ & 779 & 763 & $\mathrm{x}$ & - & $\mathrm{x}$ & - \\
\hline 23 & 814 & 813 & 814 & 675 & 677 & - & 677 & - & 677 & 674 & - & 682 & - \\
\hline 24 & 801 & 801 & 803 & - & - & - & - & - & - & - & - & - & - \\
\hline 25 & 761 & 762 & 761 & - & - & - & - & - & - & - & - & - & - \\
\hline 26 & 699 & 699 & 699 & - & - & - & - & - & - & - & - & - & - \\
\hline 27 & 675 & 676 & 672 & - & - & - & - & - & - & - & - & - & - \\
\hline
\end{tabular}

Note: $\mathrm{x}$ - wave number not set. 
compounds, while their longevity also depends on the nature of the used binder.

In this case, the least changes were captured in STG50 coating containing $13 \%$ acrylic styrene copolymer without the discussed components. Significant changes occurred in THR01 and STD05 coatings (polyvinyl acetate resin-based: $28 \%$ and $20 \%$, respectively) and, considering the changes in the number of waves, the number of peaks decreased, and new peaks characterising new compounds formed. Then, main materials determining the height of the thermal insulating foam, such as ammonium polyphosphate, melamine and pentaerythritol whereon the efficiency (fire resistance) of coating is dependent, are essentially changed or eliminated after aging.

\section{Conclusions}

The performance of SEM analysis of intumescent fire protective and combined paint coatings revealed that with the increasing number of artificial aging cycles under regime I, the amount of surface damages and their variety has increased. The prevailing surface defects include cavities, cracks, fractures, flaking, delamination and new formations in the shape of precipitate. Similar micro-defects occurred when aging the coatings for 12 months in the outdoor room under the roof. Precipitate on coating surfaces forms as a result of mass and heat exchange processes, when paint components interact with water, however, components regulating the formation of intumescent coatings, such as ammonium polyphosphate, melamine, pentaerythritol and others, are washed out to the surface, leaving cavities and cracks in coatings, no longer performing their function to form high-quality thermal insulation during a fire.

The thermal analysis revealed that compared to unaged coatings, mass losses in intumescent fire protective coatings artificially aged for 60 cycles under regimes I and II significantly increase in the interval of low temperatures ranging from $20^{\circ} \mathrm{C}$ to $600{ }^{\circ} \mathrm{C}$, and more under regime II than I. Six endothermic effects at temperatures of $71.7^{\circ} \mathrm{C}$, $118^{\circ} \mathrm{C}, 185.5^{\circ} \mathrm{C}, 230.5^{\circ} \mathrm{C}, 310^{\circ} \mathrm{C}$ and $322^{\circ} \mathrm{C}$ are very obvious in the DTA curve of unaged intumescent fire protective coating THR01. Six endothermic effects are also typical of the same coatings artificially aged under regimes I and II, however, the location of temperature peaks differs. These changes confirm the washout of the said components and their chemical changes.

The analysis of composition of FT-IR microscopy released gas (research conducted in nitrogen environment) showed that when heating unaged THR01coating, gas and/or vapour are intensively released from the coating having reached $200{ }^{\circ} \mathrm{C}$. The analysis of the chemical composition of FT-IR microscopy revealed that after artificial aging cycles under regimes I and II, changes in chemical substances were captured in all cases compared to control samples. Judging from the number of waves and the intensity of peaks, certain new connections form in aged samples, while others change or disappear. This shows the formation of certain compounds and the change or disintegration of other compounds under the influence of environmental factors (temperature and humidity fluctuations).

It was determined that after 12 months of natural aging, the fire resistance of intumescent fire protective coatings decreased from $8.2 \%$ to $35.1 \%$, meanwhile, the fire resistance after 60 artificial aging cycles according regime I decreased from $14.1 \%$ to $53.8 \%$, thus these coatings can be stated not to be long-lived, when they are affected by changes in temperature and moisture.

According to the mass losses (samples were heated at $600{ }^{\circ} \mathrm{C}$ temperature), it was found that control samples of STD05 coating have the largest mass losses, but after aging, mass losses compared with STG50 coating are similar and with THR01 coating are much lower. The mass losses of STD05 coating after aging according regime I increased by $9.9 \%$, and according regime II increased by $15.8 \%$. The mass losses of STG50 coating after aging according regime I increased by $9.4 \%$, and according regime II increased by $11.4 \%$. The mass losses of THR01 coating after aging according regime I increased by $22.7 \%$, and according regime II increased by $24.8 \%$. From the results obtained, that is strong correlation between mass losses and decrease of fire resistance.

\section{References}

Andersson, A.; Lundmark, S. H. J.; Maurer, F. 2007. Evaluation and characterization of ammoniumpolyphosphate-pentaerythritol-based systems for intumescent coatings, Journal of Applied Polymer Science 104(2): 748-753. https://doi.org/10.1002/app.25588

Bilotta, A.; de Silva, D.; Nigro, E. 2016. Tests on intumescent paints fir fire protection of existing steel structures, Construction and Building Materials 121: 410-422.

https://doi.org/10.1016/j.conbuildmat.2016.05.144

Bodzay, B.; Bocz, K.; Bárkai, Z.; Marosi, G. 2011. Influence of rheological additives on char formation and fire resistance of intumescent coatings, Polymer Degradation and Stability 96(3): 355-362.

https://doi.org/10.1016/j.polymdegradstab.2010.03.022

Brunner, S.; Richner, P.; Muller, U.; Guseva, O. 2005. Accelerated weathering device for service life prediction for organic coatings, Polymer Testing 24: 25-31.

https://doi.org/10.1016/j.polymertesting.2004.08.001

Buika, G.; Getautis, V.; Martinaitis, V.; Rutkauskas, K. 2007. Organic compounds spectroscopy. Vitae Litera.

Chemistry Encyclopedia. 2015. Vilnius: Mokslo ir enciklopedijų leidybos centras (in Lithuanian).

Darginavičienè, R.; Drungilienè, D. 2008. Slaugytojų emocinė būsena slaugant mirštančiuosius [Emotional state of nurses in the care of the dying], Sveikatos mokslai [Health Science] 6(4): 2084-2089 (in Lithuanian).

Deflorian, F.; Rossi, S.; Fedel, M. 2008. Organic coatings degradation: Comparison between natural and artificial weathering, Corrosion Science 50: 2360-2366.

https://doi.org/10.1016/j.corsci.2008.06.009 
Deflorian, F.; Rossi, S.; Fedrizzi, L.; Zanella, C. 2007. Comparison of organic coating accelerated tests and natural weathering considering meteoroligical data, Progress in Organic Coatings 59: 244-250. https://doi.org/10.1016/j.porgcoat.2006.09.036

Dimanshteyn, F. A.; Barone, R. J. 2006. Intumescent materials. World intellectual property organization. WO 2006/039275 A2.

Duquesne, S.; Magnet, S.; Jama, C.; Delobel, R. 2005. Thermoplastic resins for thin film intumescent coatings towards a better understanding of their effect on intumescence efficiency, Polymer Degradation and Stability 88: 63-69. https://doi.org/10.1016/j.polymdegradstab.2004.01.026

EN 1363-1:2012 Fire-resisitance tests. Elements of building construction. Part 1: General requirements. European Standard, 2012.

EN 1363-2:2000 Fire resistance tests - Part 2: Alternative and additional procedures. (Resistance Tests). European Standard, 2000.

EN ISO 11357-1:2010 Plastics. Differential scanning calorimetry (DSC). Part 1: General principles. European Standard, 2010.

EN ISO 11358-1:2014 Plastics. Thermogravimetry (TG) of polymers. Part 1: General principles. European Standard, 2014.

EN ISO 12944-2:2000 Paints and varnishes - Corrosion protection of steel structures by protective paint systems. Part 2: Classification of environments. European Standard, 2000.

EN ISO 2178:2016 Non-magnetic coatings on magnetic substrates. Measurement of coating thickness. Magnetic method. European Standard, 2016.

Fedel, M.; Rosso, S.; Deflorian, F. 2013. Comparison between natural and artificial weathering of e-coated galvanized steel panels, Progress in Organic Coatings 76: 194-203. https://doi.org/10.1016/j.porgcoat.2012.09.006

Grigonis, M.; Praniauskas, V.; Mačiulaitis, R. 2012. Ageing of fire coatings, International Review of Civil Engineering 3(1): 72-78.

Hairston, G.; Burns, J.; Stidham, W.; Van Voorhis, K. 2006. Intumescent flame retardant compositions. World intellectual property organization. WO 2006/017814 A1.

Hill, J. E. 1993. Intumescent coating and method of manufacture. World intellectual property organization. WO 93/20156.

Jimenez, M.; Duquesne, S.; Bourbigot, S. 2006. Characterization of the performance of an intumescent fire protective coating, Surface Coating Technology 201(3-4): 979-987.

https://doi.org/10.1016/j.surfcoat.2006.01.026

Knunjanc, I. (Ed.). 2000. Large encyclopedic dictionary. Chemistry. Moskow: „Bol'shaya Rossiyskaya entsiklopediya“ (in Russian).

Li, G.; Liang, G.; He, T.; Yang, Q.; Song, X. 2007. Effects of EG and MoSi2 on thermal degradation of intumescent coating, Polymer Degradation and Stability 92: 569-579. https://doi.org/10.1016/j.polymdegradstab.2007.01.018

Mačiulaitis, R. 1997. Frost resistance and durability of ceramic facade products: Monograph. Vilnius: Technika (in Russian).

Mačiulaitis, R.; Jefimovas, A.; Zdanevičius, P. 2012. Research of natural wood combustion and charring processes, Journal of Civil Engineering and Management 18(5): 631-641. https://doi.org/10.3846/13923730.2012.720935

Palm, M.; Carlsson, B. 2002. New accelerated weathering tests including acid rain, Journal of Coatings Technology 74: 69-74. https://doi.org/10.1007/BF02720142

Stankevičius, V. 1997. Humidity and frost resistance of building partitions: Monograph. Kaunas: Technologija (in Lithuanian).
Wang, D.; Liu, Y.; Wang, Y. C.; Artiles, P.; Hull, T. R.; Price, D. 2007. Fire retardancy of a reactively extruded intumescent flame retardant polyethylene system enhanced by metal chelates, Polymer Degradation and Stability 92: 1592-1598. https://doi.org/10.1016/j.polymdegradstab.2007.04.015

Wang, L.; Song, W.; Zhang, M.; Zhen, C. 2014. Study and prediction for the fire resistance of acid corroded intumescent coating, Procedia Engineering 84: 524-534. https://doi.org/10.1016/j.proeng.2014.10.464

Zhang, C.; Li, G. Q.; Wang, Y. C. 2014. Probabilistic analysis of steel columns protected by intumescent coatings subjected to natural fires, Structural Safety 50: 16-26. https://doi.org/10.1016/j.strusafe.2014.03.005

Zhou, S.; Song, L.; Wang, Z.; Hu, Y.; Xing, W. 2008. Flame retardation and char formation mechanism of intumescent flame retarded polypropylene composites containing melamine phosphate and pentaerythritol phosphate, Polymer Degradation and Stability 93: 1799-1806. https://doi.org/10.1016/j.polymdegradstab.2008.07.012

Žukas, A.; Mačiulaitis, R.; Šukys, R. 2007. Statybos produktu panaudojimo gaisriné sauga [Fire safety of using construction products]. Vilnius: Technika (in Lithuanian). 